\title{
An Overview on the Improvement of Mechanical Properties of Ceramics Nanocomposites
}

\author{
J. Silvestre, ${ }^{1}$ N. Silvestre, ${ }^{2}$ and J. de Brito ${ }^{1}$ \\ ${ }^{1}$ CERis-ICIST, Department of Civil Engineering, Architecture and Georesources, Instituto Superior Técnico, Universidade de Lisboa, \\ Av. Rovisco Pais, 1049-001 Lisbon, Portugal \\ ${ }^{2}$ LAETA, IDMEC, Department of Mechanical Engineering, Instituto Superior Técnico, Universidade de Lisboa, Av. Rovisco Pais, \\ 1049-001 Lisbon, Portugal \\ Correspondence should be addressed to N. Silvestre; nsilvestre@ist.utl.pt
}

Received 4 September 2015; Accepted 24 November 2015

Academic Editor: Konstantinos I. Tserpes

Copyright (C) 2015 J. Silvestre et al. This is an open access article distributed under the Creative Commons Attribution License, which permits unrestricted use, distribution, and reproduction in any medium, provided the original work is properly cited.

Due to their prominent properties (mechanical, stiffness, strength, thermal stability), ceramic composite materials (CMC) have been widely applied in automotive, industrial and aerospace engineering, as well as in biomedical and electronic devices. Because monolithic ceramics exhibit brittle behaviour and low electrical conductivity, CMCs have been greatly improved in the last decade. CMCs are produced from ceramic fibres embedded in a ceramic matrix, for which several ceramic materials (oxide or non-oxide) are used for the fibres and the matrix. Due to the large diversity of available fibres, the properties of CMCs can be adapted to achieve structural targets. They are especially valuable for structural components with demanding mechanical and thermal requirements. However, with the advent of nanoparticles in this century, the research interests in CMCs are now changing from classical reinforcement (e.g., microscale fibres) to new types of reinforcement at nanoscale. This review paper presents the current state of knowledge on processing and mechanical properties of a new generation of CMCs: Ceramics Nanocomposites (CNCs).

\section{Introduction}

It is widely recognised that ceramic matrix composites (CMCs) are extremely valuable materials for applications with demanding mechanical and thermal requirements. Despite the fact that ceramic matrices often present brittle behaviour, CMCs have been developed to achieve quasiductile fracture behaviour and maintain all other advantages of monolithic ceramics at high temperatures. For instance, CMCs can be fabricated as strong as metals, but they are much lighter and can withstand much higher temperatures. These advantages led to their application in automotive and aerospace engineering (components and aircraft engine platforms; see Figure 1).

On the opposite side, there are many ceramic products in construction industry, like floor, wall and roofing tiles, cement, or bricks, but the level of sophistication of these products is still low. Due to the large scale and multibillion dollar industry, it is expected that construction and associated manufacturing companies will invest in CMCs for building and structural components.

There are many different types of CMCs. The classification is usually done according to the matrix and fibre materials, separated by a slash. For example, $\mathrm{C} / \mathrm{SiC}$ is a ceramic matrix composite made of carbon fibres and a silicon carbide matrix. Besides these types of matrices and fibre materials, the classification usually separates ceramic matrix composites in oxide and nonoxide composites. Table 1 shows the main materials used as ceramic matrix composites according to that classification. As shown in the examples, oxide fibres are usually combined with oxide matrices and nonoxide fibres with nonoxide matrices. Thus, the main $\mathrm{CMC}$ types are $\mathrm{C} / \mathrm{C}, \mathrm{C} / \mathrm{SiC}, \mathrm{SiC} / \mathrm{SiC}$, and $\mathrm{Ox} / \mathrm{Ox}$, where $\mathrm{Ox}$ represents one of the oxide materials presented in Table 1.

When nanotechnology was introduced in the production of CMCs and analysis went from micro to nanoscale (composites to nanocomposites), some of the previously existing 


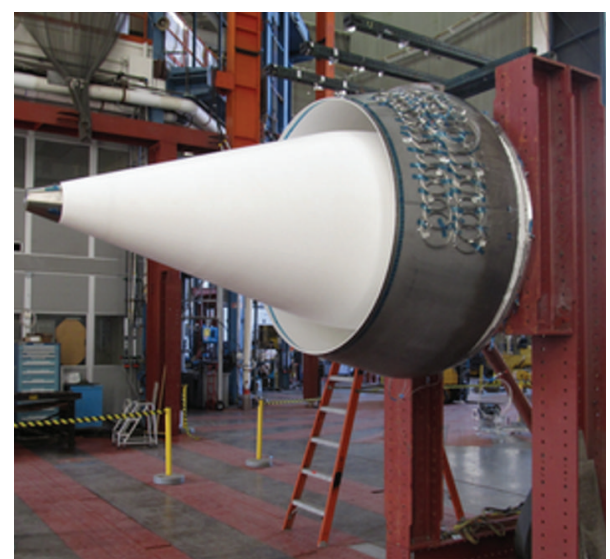

FIgURE 1: Oxide ceramic matrix composites exhaust ground test demonstrator consisting of a $1.60 \mathrm{~m}$ diameter nozzle (showing underneath the titanium-alloy faring) and $1.14 \mathrm{~m}$ diameter by $2.34 \mathrm{~m}$ conical centerbody with titanium end cap inspection portal (Courtesy of Wiley, Steyer [1]).

TABLE 1: Brief overview of CMCs reported in the literature.

\begin{tabular}{|c|c|c|c|}
\hline \multicolumn{2}{|c|}{ Ceramic matrix composites } & Materials & References \\
\hline \multirow{6}{*}{ Matrix } & \multirow{2}{*}{ Nonoxide } & Silicon carbide & {$[2,3]$} \\
\hline & & Carbon & {$[4]$} \\
\hline & \multirow{4}{*}{ Oxide } & Alumina & {$[5,6]$} \\
\hline & & Zirconia & {$[7]$} \\
\hline & & Mullite & [8] \\
\hline & & Aluminosilicates & [9] \\
\hline \multirow{5}{*}{ Fibres } & \multirow{5}{*}{ Nonoxide } & Carbon & {$[10]$} \\
\hline & & Silicon carbide & [11-13] \\
\hline & & Alumina & {$[8]$} \\
\hline & & Mullite & [14] \\
\hline & & Zirconia & {$[15]$} \\
\hline
\end{tabular}

materials lost impact and others arose. For example, the introduction of CNTs $[16,17]$ and graphene nanosheets $[18,19]$ in CMCs led to great interest of the research community due to the outstanding inherent mechanical, thermal, and electrical properties of these materials. Authors reported remarkable improvements in properties like hardness, toughness, strength, damping, and thermal conductivity over monolithic ceramics by using these types of fillers. For example, in the case of alumina CMCs, Fan et al. [20] reported an improvement of approximately $100 \%$ in fracture toughness and $20 \%$ in flexural strength with the addition of only $1 \mathrm{wt} \%$ singlewalled carbon nanotubes (SWCNTs). Moreover, Walker et al. [21] reported an increase of approximately $235 \%$ (from $~ 2.8$ to $\sim 6.6 \mathrm{MPa}$ ) at $\sim 1.5 \%$ graphene platelets volume fraction.

As concluded from these preliminary remarks, the topic of Ceramics Nanocomposites (CNCs) is growing fast and the next years will demonstrate the need for a continuous and updated review on this theme. The objective of this paper is to bring to the scientific community a state-of-the-art review on the main developments and trends in CNCs. From the search carried out in scientific databases, this review is focused on the most effective strengthening nanoparticles and the corresponding CNCs, which are

(i) silica carbide ( $\mathrm{SiC})$;

(ii) zirconia;

(iii) carbon nanotubes (CNTs);

(iv) graphene.

\section{SiC-Based CNCs}

Silicon carbide $(\mathrm{SiC})$ is one of the most promising structural materials due to its superior thermomechanical properties, such as high chemical and thermal stability, good chemical inertness, high thermal conductivity, high hardness, low density, and low coefficient of thermal expansion [22]. Silicon carbide is a compound of silicon and carbon with chemical formula SiC. It occurs in nature as mineral moissanite. Because of the rarity of natural moissanite, most silicon carbides are synthetic. $\mathrm{SiC}$ is part of a family of materials that exhibit a one-dimensional polymorphism called polytypism. Thanks to its structure, an almost infinite number of SiC polytypes are possible, and more than 200 have already been discovered [23]. With the introduction of nanotechnology and manipulation at nanoscale, new opportunities have been opened. One-dimensional (1D) nanostructures such as nanowires or nanotubes have gained much interest in fundamental research as well as tremendous potential applications. Among many materials, SiC-based 1D nanostructures have very interesting physical, chemical, and electronic properties. $\mathrm{SiC}$ is a wide band gap semiconductor, from $2.2 \mathrm{eV}$ to $3.4 \mathrm{eV}$ depending on the polytype with a high electronic mobility and thermal conductivity. One of the other merits of $\mathrm{SiC}$ is that it can be used at high temperatures because its noncongruent melting point reaches $3100^{\circ} \mathrm{K}$ and its maximal operating temperature is considered to be $1200^{\circ} \mathrm{K}$ [24]. Moreover, $\mathrm{SiC}$ is resistant to corrosive environments because of its chemical inertness. These facts justify the high application of $\mathrm{SiC}$ in a wide range of areas, such as electronics, heating elements, and structural materials. More particularly, SiC nanoparticles have been introduced in CMCs to enhance the mechanical and thermal properties of ceramic materials such as $\mathrm{Al}_{2} \mathrm{O}_{3}$ and mullite. The purpose now is to present some examples of the main improvements achieved with these nanoadditions in ceramic materials and to evaluate how these improvements can be incorporated in ceramic products used in construction industry.

In terms of thermal behaviour and electrical conductivity, Parchovianský et al. [25] studied the influence of SiC nanoparticles additions on the electrical and thermal conductivity of $\mathrm{Al}_{2} \mathrm{O}_{3} / \mathrm{SiC}$ micro-/nanocomposites under normal and high temperatures. Different samples with various volume fraction of $\mathrm{SiC}$ ranging from $3 \mathrm{vol} \%$ to $20 \mathrm{vol} \%$ were prepared by hot pressing at $1740^{\circ} \mathrm{C}$ and at $30 \mathrm{MPa}$ pressure in an argon atmosphere. The results showed that the thermal properties (thermal diffusivity and thermal conductivity) of $\mathrm{Al}_{2} \mathrm{O}_{3} / \mathrm{SiC}$ nanocomposites were not influenced by the size and shape of $\mathrm{SiC}$ particles but by the volume content of these particles. Thermal conductivity increased with higher contents of $\mathrm{SiC}$ nanoparticles up to a maximum 


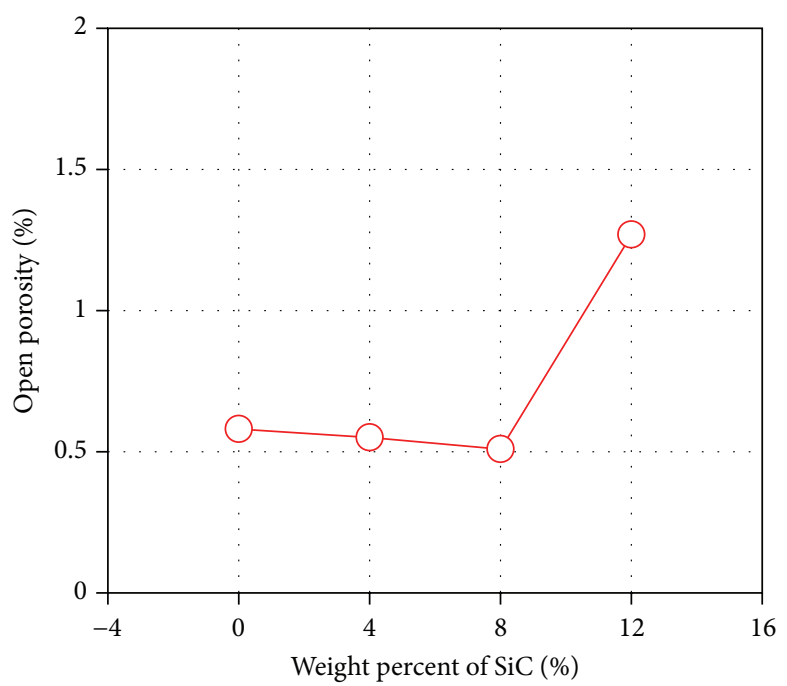

(a)

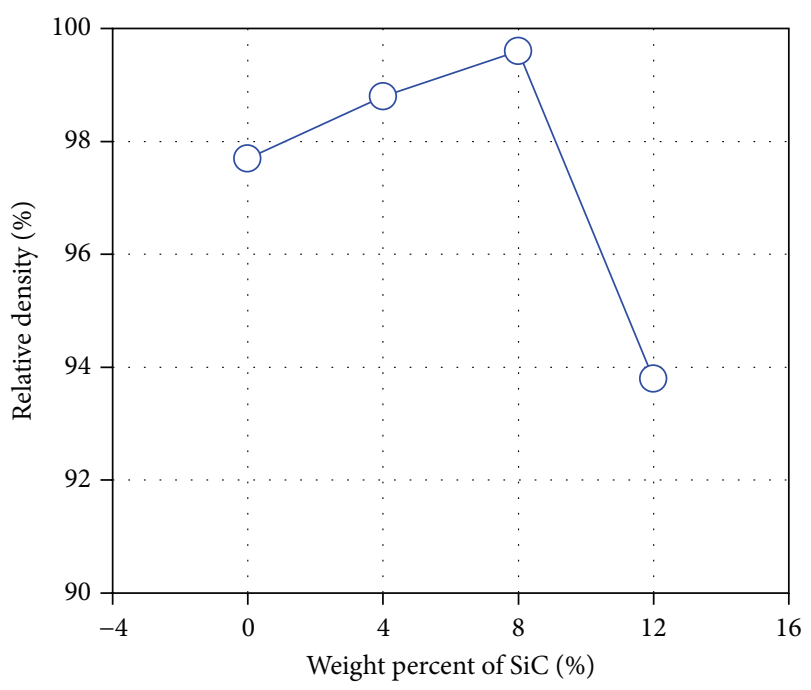

(b)

Figure 2: (a) Open porosity and (b) relative density of SiC-AlON composites measured via the Archimedes principle versus amount of SiC particles [22].

of $35 \%$ increase (from $28 \mathrm{~W} / \mathrm{m} \mathrm{K}$ to $38 \mathrm{~W} / \mathrm{m} \mathrm{K}$ ) for 20 vol\% of these nanoparticles. Barea et al. [26] obtained similar trends for these properties. However, if compared with the theoretical values of thermal conductivity reported for $\mathrm{SiC}$ $(700 \mathrm{~W} / \mathrm{m} \mathrm{K})$ or the value measured for a polycrystalline hot pressed $\mathrm{SiC}(270 \mathrm{~W} / \mathrm{m} \mathrm{K})$, the resulting thermal conductivity of a composite with $20 \mathrm{vol} \%$ of $\mathrm{SiC}$ should be much higher. Hasselman and Johnson [27] stated that the existence of a thermal barrier resulted from unperfected thermal contacts at the matrix/dispersion interfaces, partially explained by the difference of thermal expansion coefficients of the two phases. Still, a relevant increase was achieved with the inclusion of $\mathrm{SiC}$ nanoparticles. Regarding electrical conductivity, Parchovianský et al. [25] also showed that the electrical conductivity increased with higher amounts of $\mathrm{SiC}$ nanoparticles, especially in the composites with the volume fraction of $\mathrm{SiC}$ higher, or equal to $10 \mathrm{vol} \%$. The results indicated that at low $\mathrm{SiC}$ contents the $\mathrm{SiC}$ particles were not interconnected to form a continuous conductive network which was verified for amounts higher than $10 \%$, when an increase from $10^{-5} \mathrm{~S} / \mathrm{m}$ (for $5 \mathrm{vol} \%$ ) to $10^{-3} \mathrm{~S} / \mathrm{m}$ (for $10 \mathrm{vol} \%$ ) was recorded. Other studies testified identical trends, such as those of Sawaguchi et al. [28] or Stauffer and Aharony [29] that, based on mathematical models, proposed a value of $17 \mathrm{vol} \%$ of addition of a secondary phase to create an effective conductive path.

Regarding the mechanical properties of $\mathrm{SiC}$ ceramic nanocomposites, Zhao et al. [22] investigated processing and mechanical behaviour of $\mathrm{SiC}$, aluminium oxynitride $(\mathrm{AlON})$ nanocomposites. AlON is widely used as ceramic material due to its high stiffness, good chemical stability and superior corrosion and wear resistances. However, its low flexural strength and poor fracture toughness justify the incorporation of nanoadditions in the production of these types of CNCs. In this study, four samples were tested with $0 \mathrm{wt} \%, 4 \mathrm{wt} \%, 8 \mathrm{wt} \%$, and $12 \mathrm{wt} \%$ contents of $\mathrm{SiC}$. The results showed interesting indicators. Concerning microstructure and density, the authors reported a decrease in the number of visible pores with the addition of $\mathrm{SiC}$ up a maximum reduction for $8 \mathrm{wt} \% \mathrm{SiC}$ sample. For $12 \mathrm{wt} \%$, an increase in the number of pores was observed, in accordance with similar works such as Dong et al. [30], where a decrease in relative density was registered for higher contents of $\mathrm{SiC}$ (more than $10 \mathrm{wt} \%)$. Complementarily, a similar trend was observed for open porosity and relative porosity as shown in Figure 2.

Figure 2 shows that the open porosity decreased with the increasing content of $\mathrm{SiC}$ nanoparticles up to $8 \mathrm{wt} \%$ and then increased with additional $\mathrm{SiC}$ up to $12 \mathrm{wt} \%$. Accordingly, the relative density showed an opposite trend. The authors proposed some explanations for these facts, namely, the agglomeration of $\mathrm{SiC}$ nanoparticles in these composites for higher addition amounts. Moreover, Djenkal et al. [31] also reported that additional amounts of $\mathrm{SiC}$ would bring a sintering inhibiting effect on the ceramic matrix, due to the strong covalent nature of $\mathrm{Si}-\mathrm{C}$ bond, which makes it harder to fabricate self-bonded $\mathrm{SiC}$ ceramics below $2100^{\circ} \mathrm{C}$ [32].

Regarding the mechanical properties, the microhardness and Young's modulus of SiC-AlON composites were also evaluated. Figures 3(a) and 3(b) show that both microhardness and Young's modulus increased with increasing the addition of $\mathrm{SiC}$ nanoparticles up to $8 \mathrm{wt} \%$ and then significantly decreased for $12 \mathrm{wt} \%$, showing a direct relationship between mechanical properties and microstructure (density) of SiCAlON nanocomposites. Moreover, Smirnov and Bartolomé [33] also reported that the presence of porosity generally has a negative influence on the mechanical properties, due to the concentration of stress in pores, resulting in lower strength. In addition, the authors registered similar results for flexural strength and fracture toughness. The flexural and fracture toughness were $35 \%$ and $24 \%$ higher in comparison to pure AlON for an optimum content of $8 \mathrm{wt} \%$ addition. From these results, two main ideas should be emphasized from the use of $\mathrm{SiC}$ nanoparticles: (i) almost all properties of monolithic 


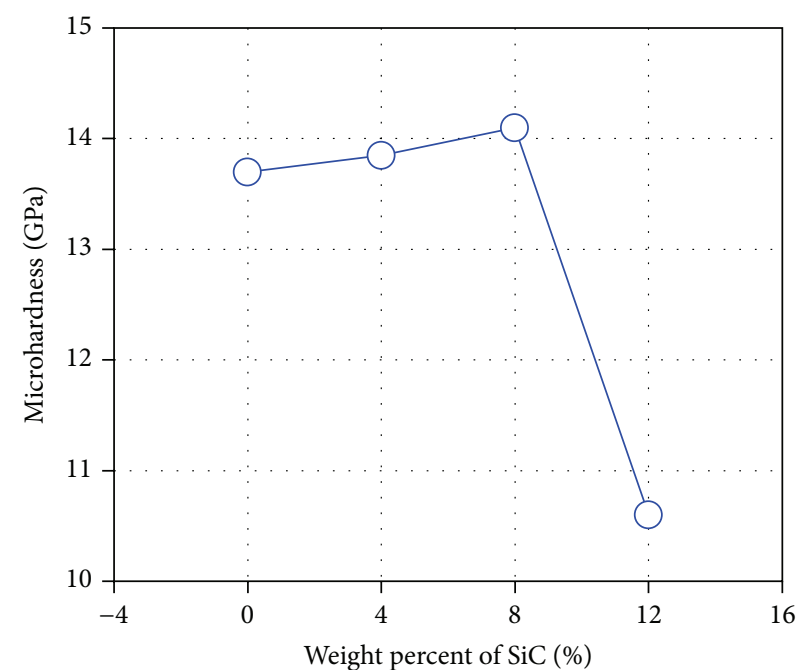

(a)

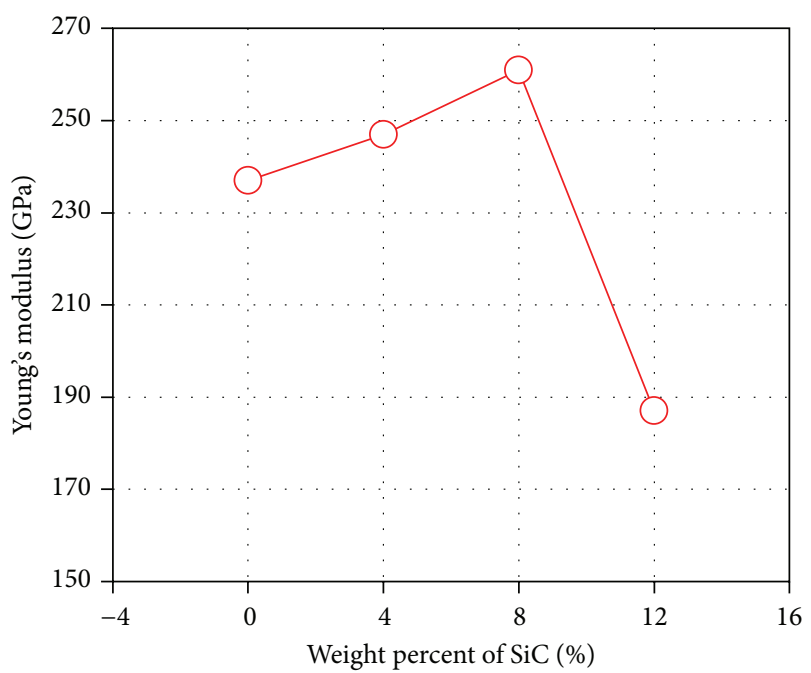

(b)

FIGURE 3: (a) Microhardness and (b) Young's modulus as a function of the content of SiC particles in SiC-AlON composites [22].

ceramics are enhanced, such as the thermal, mechanical, and electrical ones as well as the microstructure, but an optimum value of $8-10 \mathrm{wt} \% \mathrm{SiC}$ is proposed to maximize the increase in mechanical properties and (ii) the thermal properties of ceramics with $\mathrm{SiC}$ particles improved with increasing $\mathrm{SiC}$ addition content.

According to the specific functions intended for these types of materials, a reasonable value (not higher than 10$15 \mathrm{wt} \%$ ) should be considered, in order to reconcile these two goals (optimization of strength versus maximization of thermal conductivity). Contrary to other nanomaterials, the dispersion of these $\mathrm{SiC}$ nanoparticles into a cement matrix does not seem to be a critical issue for the scientific community, justifying the high application of $\mathrm{SiC}$ in ceramics materials. For example, the CoorsTek Company [34] developed ceramic products with the application of $\mathrm{SiC}$ powders. The producers present, as key benefits and properties of $\mathrm{SiC}$ ceramics, their high thermal conductivity, low thermal expansion coefficient, extreme hardness, and chemical attack resistance, making of $\mathrm{SiC}$ a nanomaterial with high potential for reinforced ceramics materials.

\section{Zirconia-Based CNCs}

Like $\mathrm{SiC}$, zirconia $\left(\mathrm{ZrO}_{2}\right)$ is a specific material with high potential to be used in ceramic materials, due to its high ionic and thermal conductivity, in addition to mechanical properties. $\mathrm{ZrO}_{2}$ is a white crystalline oxide of zirconium. It can occur naturally or synthesized in three main phases: monoclinic, tetragonal, and cubic. In addition, zirconia is chemically unreactive. Under higher temperatures, $\mathrm{ZrO}_{2}$ adopts a tetragonal and cubic structure. $\mathrm{ZrO}_{2}$ particles are used as one of the most common fillers, leading to an increase in fracture toughness and chemical inertness. Recent studies suggest that the mechanical properties of CNCs with $\mathrm{ZrO}_{2}$ could be considerably increased by reducing the level of grain size and by achieving high levels of dispersion of these particles in the matrix. Zirconia and alumina are very often associated [35]. Zirconia Toughened Alumina (ZTA) ceramics offer an improved performance for an exceptional cost ratio. ZTA nanocomposites are attractive structural materials that combine the high hardness and Young's modulus of the alumina matrix with an additional toughening effect of the zirconia dispersion. ZTA ceramics are produced to contain $2-20 \mathrm{vol} \%$ of fine zirconia particles in an alumina matrix, with increased strength and toughness. For example, Chinelatto et al. [36] studied the effect of sintering curves on the microstructure of alumina-zirconia CNCs. The purpose of sintering advanced composites is to control the material's final microstructure with high densification with low grain growth and elimination of porosity. Different samples with 5 vol\% of nanometric $\mathrm{ZrO}_{2}$ inclusions in an alumina matrix were tested. The results showed an important influence of the temperature on the grain size and growth. An increase of approximately 2.5 times (from $1000 \mathrm{~nm}$ to $2500 \mathrm{~nm}$ ) was observed in the mean grain size with two distinct sintering procedures: $1500^{\circ} \mathrm{C}$ and $1600^{\circ} \mathrm{C}$, respectively. These results have important consequences on the mechanical properties of CNCs that are summarized next. Most studies focus the toughening mechanisms in CNCs. For example, Benavente et al. [35] registered an increase from $5 \mathrm{MPa} \mathrm{m}^{1 / 2}$ to approximately $6 \mathrm{MPa} \mathrm{m}{ }^{1 / 2}$ in the fracture toughness for samples with 15 vol\% $\mathrm{ZrO}_{2}$ in alumina matrix for a sintering temperature of $1200^{\circ} \mathrm{C}$ and $1400^{\circ} \mathrm{C}$, respectively. Complementarily, as Figure 4 shows, a significant increase in hardness and Young's modulus was registered (from $9 \mathrm{GPa}$ to $20 \mathrm{GPa}$ and from $300 \mathrm{GPa}$ to $367 \mathrm{GPa}$, resp.) for samples with $10 \mathrm{vol} \%$ of $\mathrm{ZrO}_{2}$.

Zirconia can also be used as the matrix and alumina as the addition. For example, Vasylkiv et al. [15] produced zirconia ceramic with $1 \mathrm{wt} \%$ to $5 \mathrm{wt} \% \mathrm{Al}_{2} \mathrm{O}_{3}$ addition. The authors obtained an average hardness and toughness for $2.5 \mathrm{wt} \%$ alumina addition of $16.23 \mathrm{GPa}$ and $7.86 \mathrm{MPa} \mathrm{m}^{1 / 2}$, respectively. Zirconia can also play an important role as a ceramic matrix 


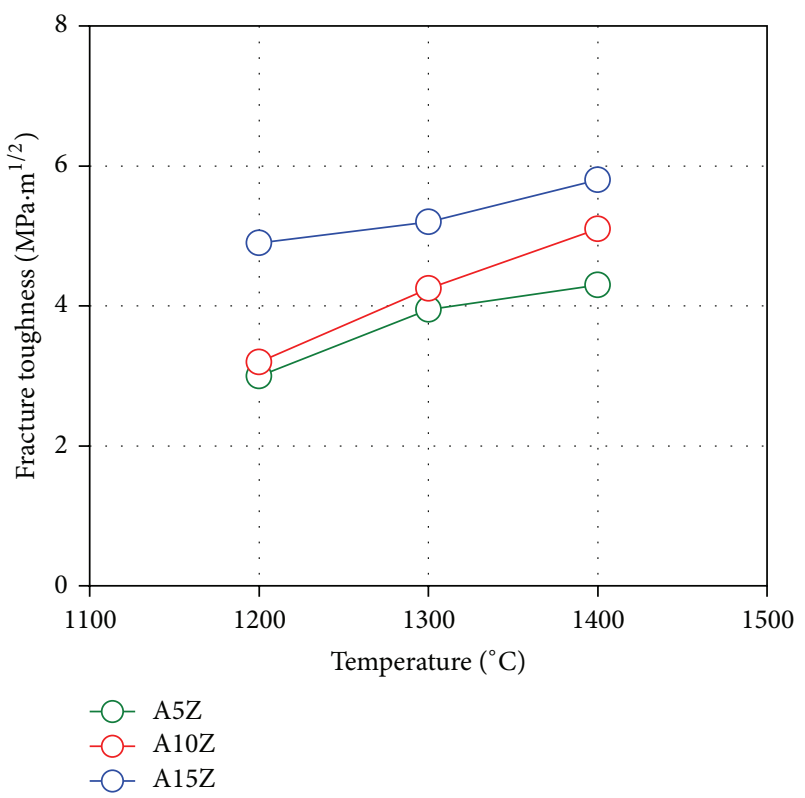

(a)

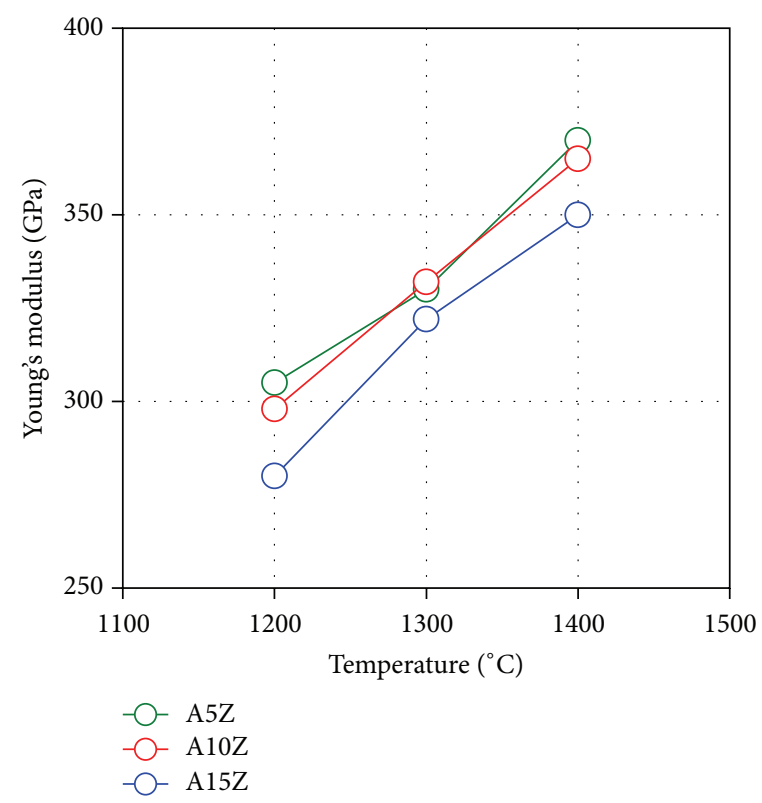

(b)

Figure 4: Influence of microwave sintering temperature on (a) fracture toughness and (b) Young's modulus of $\mathrm{Al}_{2} \mathrm{O}_{3}-\mathrm{ZrO}_{2}$ materials with different contents [35].

material. Danilenko et al. [37] studied the effect of nickel oxide $(\mathrm{NiO})$ in $\mathrm{ZrO}_{2}$ composites. The authors registered that $\mathrm{NiO}$ and inclusions can increase the indentation fracture toughness of zirconia-nickel oxide composite material more than $50 \%$, but only when the sintering occurs in a neutral atmosphere.

In this context, the CoorsTek Company [38] also developed a zirconia ceramic product named Technox zirconia [39] for application in several industries, such as refractories, telecommunications, or electronics with the following advantages: high strength, high fracture toughness, high wear resistance, good frictional behaviour, low thermal conductivity, and electrical insulation. Still, as observed for silicon carbide, if improved electrical properties are needed, other nanomaterials are more suitable, such as carbon nanotubes or graphene oxide.

\section{CNT-Based CNCs}

The excellent properties of carbon nanotubes (CNTs) together with their one-dimensional nature (high aspect ratio) dimensionality make them ideal candidates for reinforcement in almost any type of materials. CNCs are naturally included in these areas, where CNTs can be used as toughening elements to overcome the intrinsic brittleness of the ceramic materials. Thanks to their structure, CNTs tend to form complex networks of aggregates within composite materials, playing a major role in defining the mechanical, electrical, and thermal properties of the composites [40]. The majority of works addressing CNT composites were focused on polymer matrices, whilst comparatively few investigations explored inorganic (ceramic) matrices and the potential of CNTs reinforcements as toughening mechanisms. However, the increasing interest on CNTs applications and fabrication with lower cost maintain the potential of this issue. For example, Cho et al. [40] presented an extended overview on CNCs containing CNTs. According to the authors, for successful CNT/composite development, two major challenges must be considered. Primarily, CNTs with intrinsically good mechanical properties must be obtained in reasonable quantity at acceptable cost for consistent incorporation in materials production industry. Secondly, CNTs must be processed in such a way that a homogeneous dispersion is obtained within the matrix with an appropriate degree of interfacial bonding.

These requirements are naturally common to all CNT composites, but, in the case of inorganic matrix composites, such as ceramics, they play a key role in the production of CNCs with CNTs. In the case of CNCs, obtaining a high degree of inorganic matrix densification without damaging the CNTs is a widely discussed and challenging task. A good dispersion of CNTs in composites means that the individual nanotubes are distributed uniformly throughout the matrix and well-separated from each other. However, CNCs with CNTs tend to form aggregates spontaneously during the growth process. These agglomerates are extremely undesirable especially in ceramic matrices, as they may act as defects leading to stress concentration and premature failure.

Figure 5 shows the typical microstructures of agglomerated (Figure 5(a)) and homogeneous (Figure 5(b)) CNT/glass matrix composites. CNTs easily agglomerate thanks to their high aspect ratios and typically poor interaction with solvents or cement matrix composites. Within CNTs, SWCNTs are more prone to agglomerate into "ropes" or "bundles," consisting of many parallel nanotubes bound by van der Waals forces. These agglomerations lead to a decrease in mechanical and functional properties of CNCs. 

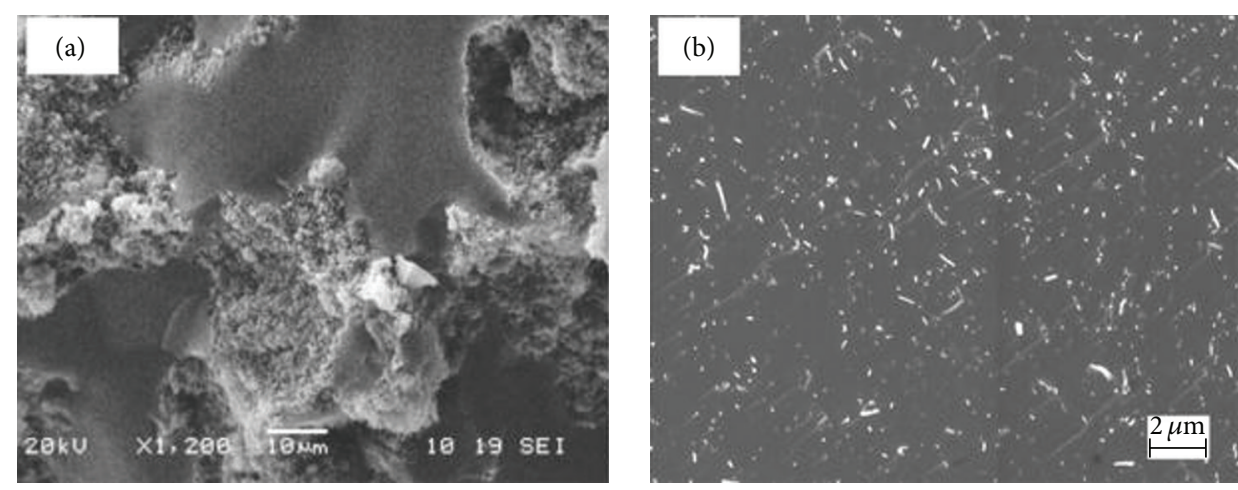

FIGURE 5: SEM images of fracture surfaces of (a) agglomerated CNTs in a borosilicate glass matrix and (b) homogeneously dispersed CNTs in a silica matrix (individually pullout CNT segments can be observed that may be related to possible toughening mechanisms) [40].

Regarding the influence of surfactants and sonication parameters on the homogeneous distribution of CNTs in ceramics, the works by Estili et al. [41] and Dassios et al. [42] must be cited. Estili et al. [41] applied a powder technology to investigate the load-carrying and reinforcing capabilities of CNT-based CNCs. They prepared surfactantless, hydrophilic, slightly disordered, crystalline, multiwalled CNTs and then incorporated them in an $\alpha$-alumina ceramic. The homogeneous incorporation of these CNTs within the alumina ceramic led to a considerable increase in the fracture toughness after spark plasma sintering (SPS), proving their effectiveness in the ceramics. The bundled CNTs observed in some dried samples were individually separated by mild ultrasonication in distilled water. Although having the same crystalline structure as in these samples, the poor dispersion observed in other slightly disordered samples was probably due to inadequate functionalization. The authors attributed this evidence to cause difficulties in surrounding effectively CNTs by water molecules, and thus CNTs cannot be redispersed after drying even by strong ultrasonication. Very recently, and in order to quantify the effects of sonication parameters on CNT length and sample polydispersity, Dassios et al. [42] suggested a straightforward methodology based on CNT agglomerate size analysis by liquid mode laser diffraction. Their methodology allowed a surfactant-assisted homogeneous dispersions of multiwalled CNTs in aqueous solutions by optimization of sonication parameters (duration, energy, and surfactant loading ratio).

Typically, high loading fractions favour agglomeration, because particles come into contact more often, which explains common results for CNCs where properties are enhanced at low loading fractions but cannot be increased further due to CNT agglomeration above a small vol\%. In fact, with good dispersion, each CNT is loaded individually over a maximum interfacial area, contributing directly to mechanical and toughening mechanisms. However, the situation becomes more ambiguous when addressing transport properties, such as electrical conductivity, as a network of touching CNTs is desired. Also in this case, the results indicate that an initial good dispersion favours these properties, allowing the network to form by itself. To overcome the problem of dispersion of CNTs issues many different approaches have been proposed ranging from ultrasonic action, functionalization of surfaces, and use of surfactants $[43,44]$. In terms of CNCs, several methods gain advantage as potential techniques to assure a good dispersion of CNTs in ceramic matrices: colloidal processing, sol-gel processing, electrophoretic deposition, in situ growth of CNTs on ceramics, and high shear compaction combined with spark plasma sintering.

Notwithstanding these dispersion issues, CNCs with addition of CNTs still attract much attention from the research community, due to potential significant improvements on mechanical and functional properties. Thanks to the brittle property of ceramic materials, most of studies aim to increase the fracture toughness. However, improvements extend to many other properties, such as flexural and bending strength, compressive strength, Young's modulus, and electrical properties. Estili and Kawasaki [45] developed an approach to mass-producing CNTs alumina composites with optimized and controlled compositions. Authors stated that homogeneous composites can only be obtained for CNT concentrations in the range of $2.4-16 \mathrm{vol} \%$. However, an increase of $70 \%$ in the fracture toughness from $3.12 \times 10^{6} \mathrm{~Pa} \cdot \mathrm{m}^{1 / 2}$ for monolithic to $5.20 \times 10^{6} \mathrm{~Pa} \cdot \mathrm{m}^{1 / 2}$ was registered only for alumina composites with $3.5 \mathrm{vol} \%$ of CNTs. Also Jiang et al. [46] produced $10 \mathrm{vol} \%$ SWCNTs- $\mathrm{Al}_{2} \mathrm{O}_{3}$ composites by the spark plasma sintering (SPS) method that exhibit excellent toughness, ranging from $6.9 \times 10^{6} \mathrm{~Pa} \cdot \mathrm{m}^{1 / 2}(221 \%)$ to $9.7 \times$ $10^{6} \mathrm{~Pa} \cdot \mathrm{m}^{1 / 2}(310 \%$ increase related to monolithic alumina composite). Regarding fracture toughness, similar results were presented by other authors $[19,47]$.

Despite these positive results, the alumina composites with CNTs addition have not been sufficiently documented and recently some contrasting results came up. For example, Aguilar-Elguézabal and Bocanegra-Bernal [48] studied the fracture behaviour of alumina ceramic reinforced with a mixture of $0.05 \mathrm{wt} \%$ MWCNTs + $0.05 \mathrm{wt} \%$ SWCNTs. Although the small amounts of CNTs added to the alumina matrix, the results showed a general decrease in Vickers hardness and fracture toughness for these samples compared to monolithic alumina matrix (Figure 6). The hardness and fracture toughness of the CNCs with different types of 


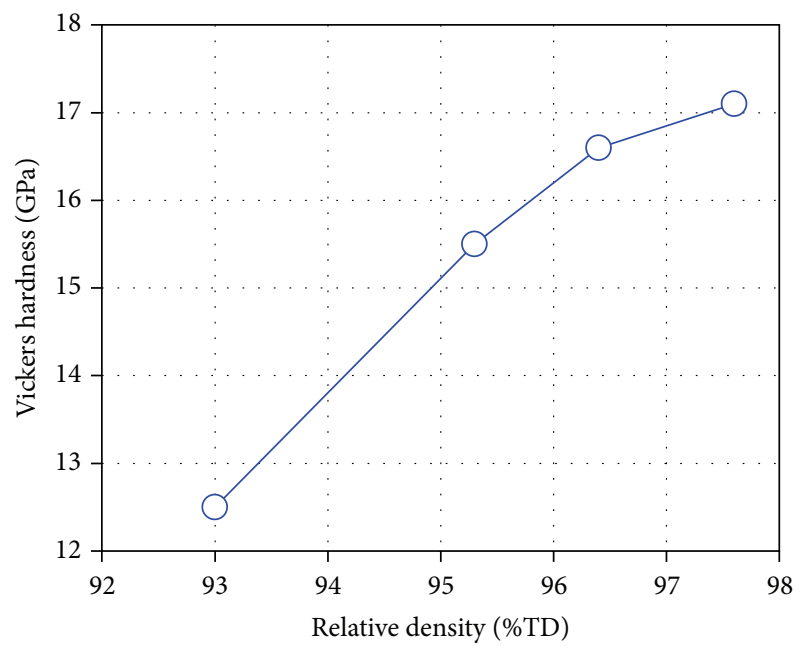

(a)

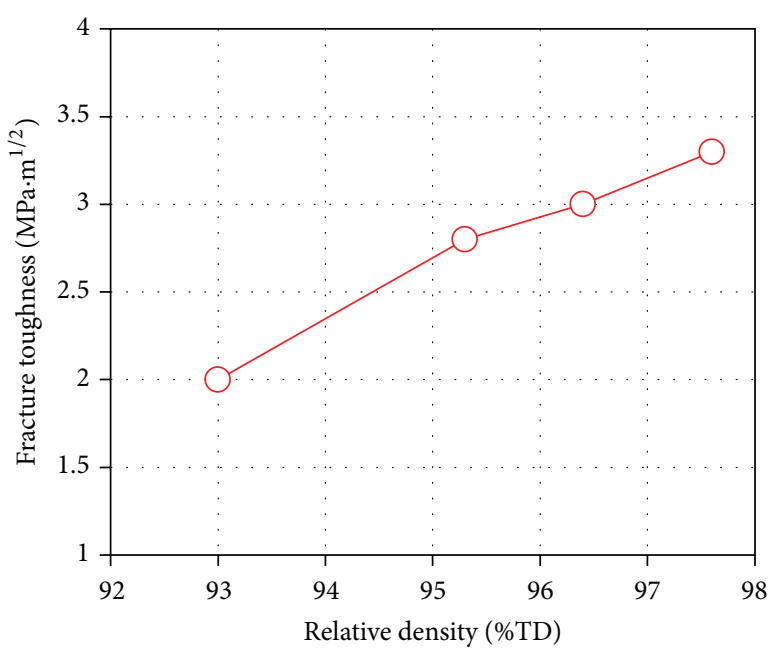

(b)

FIGURE 6: Variation of (a) Vickers hardness and (b) fracture toughness with relative density for various nanocomposites [48].

CNTs were much lower than those of pure $\mathrm{Al}_{2} \mathrm{O}_{3}(17.05 \mathrm{GPa}$ and $3.34 \times 10^{6} \mathrm{~Pa} \cdot \mathrm{m}^{1 / 2}$, resp.). The lowest hardness and fracture toughness values were registered for the composites reinforced with the mixture of SWCNTs and MWCNTs $\left(12.45 \mathrm{GPa}\right.$ and $1.96 \times 10^{6} \mathrm{~Pa} \cdot \mathrm{m}^{1 / 2}$, resp.), due to the higher porosity and the presence of clusters or bundles of CNTs that undoubtedly act as defects with no load-carrying ability.

As mentioned previously, the main difficulty to achieve a CNTs-ceramic composite is the homogeneous dispersion of CNTs in the ceramic powder. The technique proposed by Peigney et al. $[49,50]$, based on a catalysis method for the in situ production (in a composite powder) of a huge amount of CNTs bundles, was very successful. SEM observations proved that the CNT bundles were present in CNCs but in a smaller quantity than in the starting powder. Although SEM observations indicated that the CNT bundles could dissipate some fracture energy, Peigney et al. $[49,50]$ also concluded that the obtained mechanical properties were not improved because the reinforcement effect expected from the addition of very long CNT bundles was not observed.

Very recently, Dassios et al. [51] proposed a technique that combines high shear compaction and spark plasma sintering for the massive, cheap, and sustainable production of $100 \%$ dense ceramics containing CNTs. This technique was systematically found associated with $100 \%$ dense final materials, which dramatically improves current CNT-ceramic densification standards. MWCNT loadings of $0.5 \mathrm{wt} \%$ provided optimal stiffness improvement of the borosilicate glass under both shear and axial elastic loads. Due to indications of nanoscale-specific energy dissipation mechanisms, these authors propose further research on the toughening and functional aspects of the material for a wide range of reinforcing and multifunctional applications.

Also Gallardo-López et al. [52] tested the effects of SWCNTs on the hardness and flexural strength of alumina matrix composites. Samples of fully dense $\mathrm{Al}_{2} \mathrm{O}_{3}$ and SWCNTs composites with $1,2,5$, and $10 \mathrm{vol} \%$ of SWCNTs were fabricated by colloidal processing and tested. The results showed neither increase nor decrease of hardness for samples with 1 vol\% SWCNTs with respect to monolithic alumina. Moreover, a $25 \%$ decrease in hardness was found for composites with higher SWCNTs content (3, 5, and 10 vol\%). Similar trends were found for flexural strength where a significant decrease was found for samples with higher contents of SWCNTs addition ( $48.7 \%$ decrease for $2 \mathrm{vol} \%)$.

These contradicting results show that much has to be done to determine ideal experimental conditions and materials processing to obtain consistent results in the addition of CNTs in ceramic matrices. From the literature, authors put forward for reflection the following aspects.

(i) Mechanical properties are strongly affected by grain size. The CNT refinement effect on the matrix grains is greater at higher temperatures $\left(1550-1600^{\circ} \mathrm{C}\right)$ [52]. Recently, Hanzel et al. [53] developed a new approach based on the functionalization of MWCNTs by acid treatment and stabilization of alumina/MWCNT dispersion at high temperatures $\left(1550^{\circ} \mathrm{C}\right)$ with subsequent freezing. Figure 7 shows the high levels of dispersion obtained for the samples tested in this study.

(ii) Many authors $[47,54]$ questioned the validity of the method used to measure fracture toughness using the microhardness method based on the following equation:

$$
K_{l C}=\alpha\left(\frac{E}{H}\right)^{1 / 2} \cdot\left(\frac{P}{C^{3 / 2}}\right),
$$

where $E$ and $H$ are Young's modulus and hardness, respectively, $P$ is the applied load, $C$ is the radial crack length, and $\alpha$ is an empirical constant which depends on the geometry of the indenter. The authors argue that the validity of the fracture toughness results depends critically on the elastic/inelastic contactmechanical response of the material under test. 

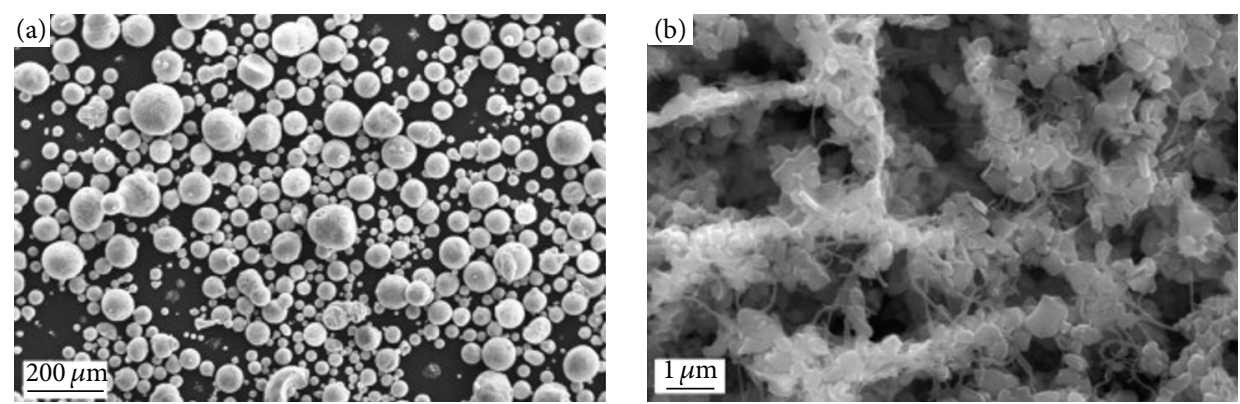

FIGURE 7: SEM images of (a) granulated alumina/CNT composite powder and (b) detail of granulate surface with distribution of MWCNTs and alumina grains [53].

According to Estili and Sakka [55], CNTs embedded in ceramic matrices experience a combination of tensile and bending loads during the bridging of the cracks of the ceramic matrix. Additionally, the rupture and/or frictional pullout of the single-walled CNT bundles during the crack bridging process contributed marginally to the energy dissipation and the mechanical improvement. Estili and Kawasaki [56] proposed a stronger intergraphene shear strength in multiwalled CNTs by embedding these into a compressivestressing ceramic environment to exploit the exceptional strength of tube inner walls during tensile loading. A relevant enhancement in the tensile failure load of multiwalled CNTs was obtained in the ceramic environment and a new "multiwall" failure mechanism was discovered. Microstructural investigations by Dassios [57] specified the existence of highly dissipating nanoscale-specific toughening mechanisms acting complementary to CNT bridging and pullout, stipulating high potential and capabilities in a wide range of reinforcing and multifunctional applications.

The before-mentioned issues should be considered and studied to fully take advantage of CNTs potential in ceramic products. Despite these important aspects, CNTs have also been tested to increase the electrical properties and structural health monitoring capabilities of CNCs. For example, Inam et al. [58] developed a novel method for analysing the structural health of alumina nanocomposites filled with graphene nanoplatelets CNTs and carbon black nanoparticles. A change in electrical conductivity was analysed after indentation to understand the structural damage and try to establish some kind of correlation. The results showed that the change in electrical conductivity is highly dependent on the type of filler and number of indentations or damage. Damage was indicated by an irreversible decrease in electrical conductivity for the indented nanocomposite bars.

Moreover, despite the massive advantage of the use of alumina as ceramic matrix in the literature, due to its high resistance to corrosion, chemical stability, and hardness, other ceramic matrices were used. For example, $\mathrm{SiO}_{2}$ matrices were used with various contents of CNTs additions and the results showed similar trends to those obtained with alumina $[59,60]$. Still, the attention of current research is mainly aimed at achieving good dispersion of CNTs in all of these types of cement matrices.

\section{Graphene-Based CNCs}

Graphene (GO) has gained increasing interest from the research community in almost all areas. However, probably due to problems with the dispersion of CNTs in CNCs, studies involving the incorporation of graphene in ceramic matrices have increased highly in the last few years. Graphene, with its combination of a large specific surface area, two-dimensional high aspect ratio sheet geometry, and increased mechanical properties, shows great potential as nanofiller in composite materials. It has been shown that graphene is mainly used to reinforce polymeric matrices, as the majority of research works have dealt with graphene-reinforced polymer matrix composites (PMCs). However, the improvements in mechanical and thermal properties in PMCs have opened new perspectives for its use in bulk ceramics. The first reports on graphene/alumina composites occurred in 2009 [61], when $5 \%$ of carbon was added to the alumina matrix via milling alumina and graphite in ethanol at room temperature. Since then, much has been done. Records of improvements involve mainly properties like fracture toughness, electrical conductivity, or Vickers hardness. For example, Centeno et al. [62] prepared $\mathrm{GO} / \mathrm{Al}_{2} \mathrm{O}_{3}$ powders and tested their mechanical and electrical properties. Regardless of the well-known problems of aggregation when reduced oxide is directly used as the second phase in hydrophilic matrices, the resulting slurries of $\mathrm{GO} / \mathrm{Al}_{2} \mathrm{O}_{3}$ showed very good dispersion. As a consequence, the authors registered good impacts in both electrical and mechanical properties. As Figure 8 shows, an increase of 50$80 \%$ in fracture strength compared to monolithic $\mathrm{Al}_{2} \mathrm{O}_{3}$ was registered. For an optimum value of $0.22 \mathrm{wt} \% \mathrm{GO}$ addition, an increase of approximately $80 \%$ was observed. Moreover, Vickers hardness of the composites was very similar to the one of the monolithic alumina. This means a good dispersion of the graphene phase that avoids the deterioration of this important property (Figure 8).

Wang et al. [64] developed another example of a graphene/alumina $\mathrm{CNC}$. GO nanoplatelets were added to an $\mathrm{Al}_{2} \mathrm{O}_{3}$ /water dispersion. Among several improvements, the authors registered an increase of approximately $53 \%$ of the fracture toughness compared to that of pure alumina. Moreover, an increase of the electrical conductivity up to $172 \mathrm{~S} \mathrm{~m}^{-1}$ was achieved. Also, Chen et al. [63] added GO 


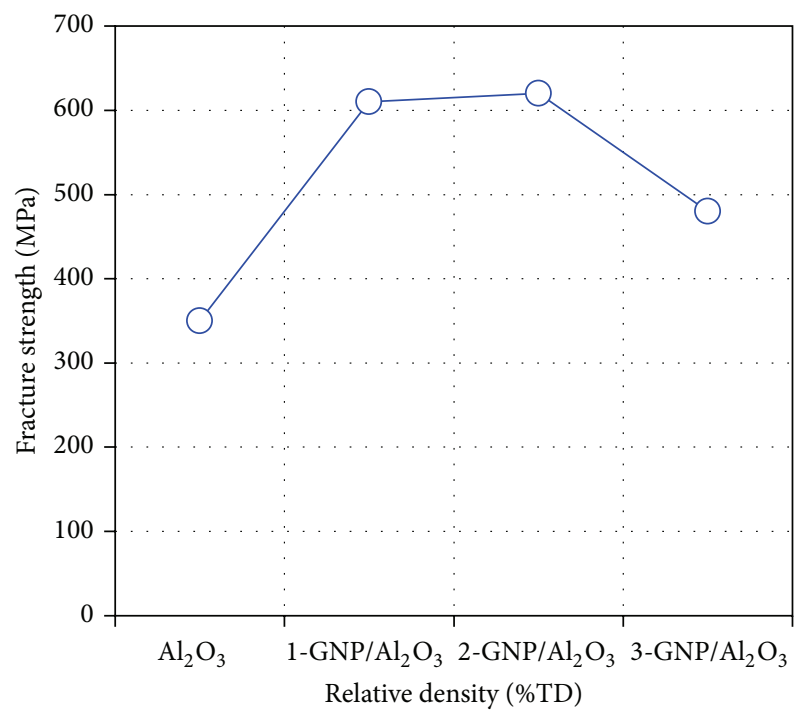

(a)

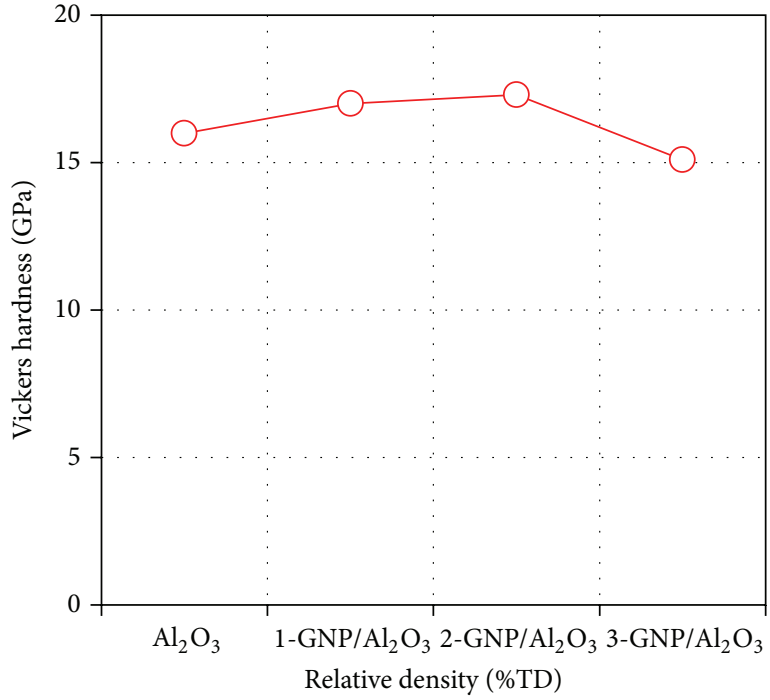

(b)

FIGURE 8: Mechanical properties of the composites and alumina: (a) fracture toughness and (b) Vickers hardness [62].

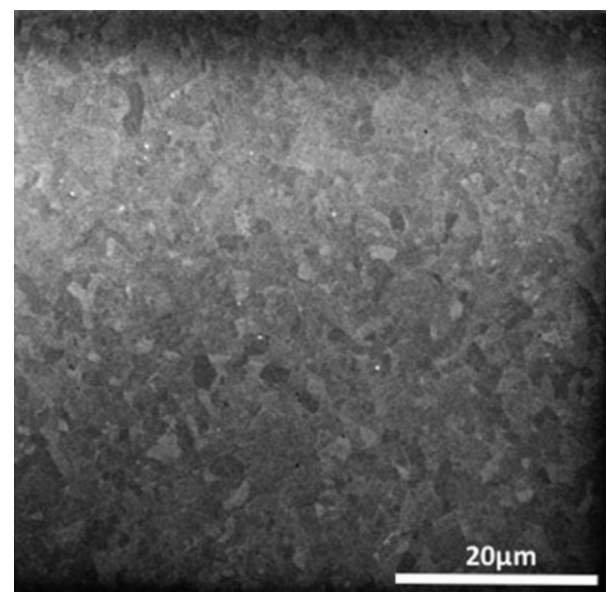

Figure 9: SEM image of $0.22 \mathrm{wt} \% \mathrm{GO} / \mathrm{Al}_{2} \mathrm{O}_{3}$ polished surface [62].

nanosheets to alumina composites by hot pressing in contents ranging from 0.1 to $1.0 \mathrm{wt} \%$. These additions had impact in almost all the properties of the resulting samples. Primarily, a decrease of approximately $20 \%$ (from $2.51 \mu \mathrm{m}$ to $2.0 \mu \mathrm{m}$ ) in average grain size was observed when $\mathrm{GO}$ was added to alumina matrix. The introduction of GO nanosheets hinders the growth of alumina particles making much finer particles resulting in more homogeneous materials as shown in Figure 9. Figure 10(a) shows large and uneven grains for the monolithic alumina. Contrarily, GO composites exhibit a remarkable decrease in grain size (Figure 10(b)).

Consequently, the authors registered an increase of approximately $43.5 \%$ of the fracture toughness for an optimum value of $0.2 \mathrm{wt} \%$ of $\mathrm{GO} /$ alumina composite. Also the bending strength increased by $28 \%$ (from $420 \mathrm{MPa}$ to $540 \mathrm{MPa}$ ) with GO addition for an optimum value $0.1 \mathrm{wt} \%$.
Moreover, GO addition has high impacts on cracks propagation. The authors registered four toughening mechanisms: crack deflection, enhanced by the large specific surface area of GO nanosheets (Figure 11(a)); crack stopping when cracking slows down or even stops by the action of graphene nanosheet (Figure 11(b)); crack bridging when GO nanosheets effectively dissipate fracture energy (Figure 11(c)); crack branching which constitutes cracks in lengths of several micrometres, which contributes to the increase of toughness (Figure 11(d)). Similar phenomena were reported by several other authors $[18,20,62,65]$.

Although the great majority of works regard the application of GO in alumina matrices, these outstanding results extend to other types of matrices. For example, Hvizdoš et al. [66] tested a series of silicon nitride based CNCs containing 1 and $3 \mathrm{wt} \%$ of four types of graphene platelets. The results showed that graphene does not tend to extensive clustering; that is, only occasional stacks are observed. This is in fact a great advantage of GO addition in ceramic matrices, especially when compared to the application of CNTs. Moreover, the incorporation of GO leads to better wear resistance. A decrease of $60 \%$ was registered in samples with $3 \mathrm{wt} \%$ addition of graphene nanosheets. Fan et al. [20] also registered a remarkable $235 \%$ improvement in fracture toughness due to the addition of only $1.5 \mathrm{vol} \%$ of graphene in silicon nitride.

Although the number of publications of GO Ceramics Nanocomposites is relatively limited when compared to other nanomaterials, such as silicon carbide or CNTs, there are no claims of a decrease in mechanical and functional properties of these nanomaterials. In fact, the potential of using these nanoparticles is so high that some authors are recently patenting processes and methods to produce these composite materials. For example, Corral et al. [67] patented novel graphenereinforced ceramic composites and methods for making such composites materials with small amounts of these nanomaterials ( 0.02 to $1.5 \mathrm{vol} \%)$. The perspectives of using 


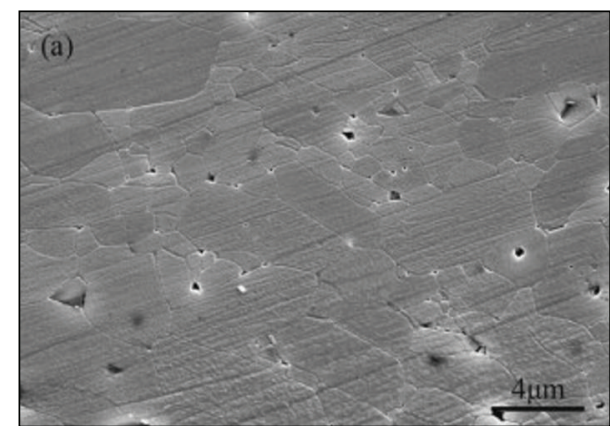

(a)

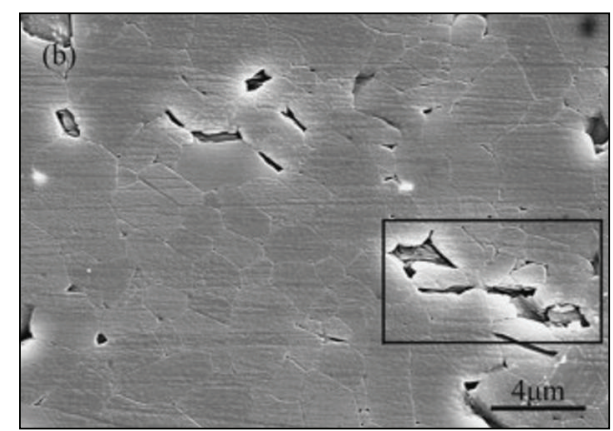

(b)

FIGURE 10: Mechanical properties of the composites and the alumina [63].

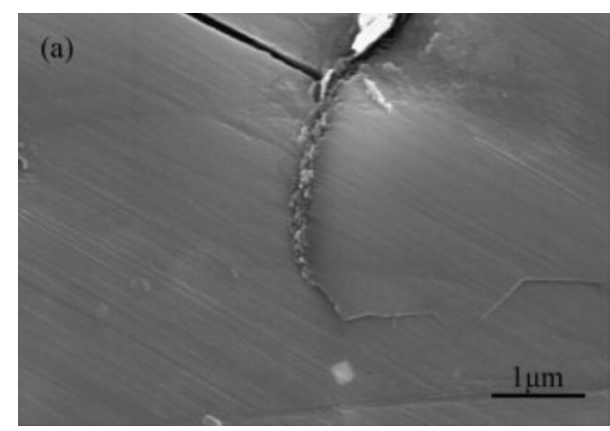

(a)

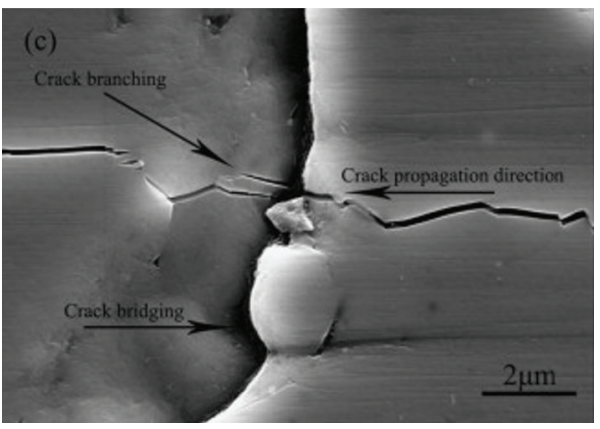

(c)

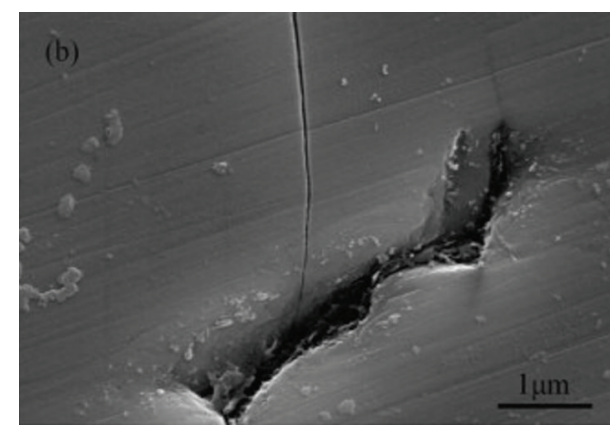

(b)

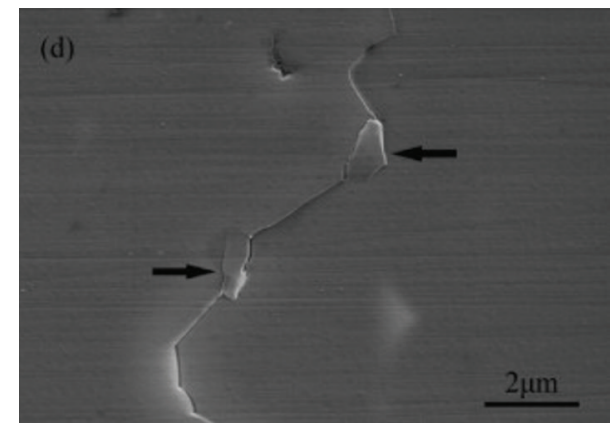

(d)

FIGURE 11: FESEM images of Vickers indentation fractured surfaces indicating the toughening mechanisms: crack deflection (a), crack stopping (b), crack bridging (c), and crack branching (d) [63].

GO in CNCs production for high temperatures applications justified their efforts to publish and protect such methods.

\section{Concluding Remarks}

This paper reviewed the current research status of the field of ceramic nanocomposites (CNCs) and recent developments in this area. The range of application of CNCs compared to polymer nanocomposites (PMCs) is considerably smaller, especially within the construction industry. Ceramics usually play a nonstructural role in construction, with the main applications ranging from floor, wall, and roofing tiles to bricks or glass. For example, ceramic tiles are used in floors and walls and similar materials are used to furnish bathrooms. These ceramic products are durable, relatively hygienic, and normally used to add aesthetical value. Additionally, for these types of applications, ceramic products show high stiffness and strength, good corrosion resistance, and low thermal and electrical conductivity. The introduction of nanotechnology has allowed increasing all of these properties. Moreover, with nanotechnology new features can be added to ceramic products. For example, the introduction of CNTs or graphene allowed some ceramics to exhibit high thermal conductivity and/or high electrical conductivity.

In terms of thermal behaviour, fracture toughness and chemical resistance, silicon carbide, zirconia, and alumina show more consistent results. Their incorporation in ceramic matrix has as a primary impact an improvement of the microstructural composition with high densification, low grain growth, and elimination of porosity. Consequently, it impacts 
other properties. For example, silica carbide shows the potential to increase the thermal behaviour up to a maximum of $35 \%$ for a 20 vol $\%$ addition. For additions under 20 vol $\%$, both silica carbide and zirconia additions increase the fracture toughness up to $35 \%$ and $50-100 \%$, respectively. Besides these improvements, the dispersion of these nanopowders in ceramic matrices is currently relatively controlled, justifying the investment of some manufacturers in producing these nanopowders, such as CoorsTek [38, 39].

Still, the biggest potential of development of hi-tech ceramic materials is the opportunity of adding carbon derived nanomaterials, particularly CNTs and graphene. Regarding CNTs, their incorporation has a tremendous impact on almost all properties of ceramic materials. For example, the results showed up to $310 \%$ increase in fracture toughness for $10 \mathrm{vol} \%$ addition of SWCNTs. Also, the electrical conductivity can increase up to $45 \%$ with the addition of CNTs for $5-15$ vol\% addition. However, the dispersion of CNTs in ceramic matrices represents a critical issue that has been preventing further developments. CNTs tend to form agglomerations, particularly in cement matrices, acting as defects leading to stress concentration and premature failure. The techniques used to process CNCs with CNTs have gradually provided better and more consistent properties compared to traditional powder processing methods. However, further developments are still required to develop higher quality samples in sufficient quantities to provide reliable results.

The problems related to the addition of CNTs enabled graphene to gain preference in the application in CNCs. The results indicate similar improvements in mechanical properties to those of CNTs, such as improvements up to $235 \%$ in fracture toughness for only $1.5 \mathrm{vol} \%$ addition. Much attention has been focused on describing the toughening mechanisms with the addition with these types of nanoparticles. Also the electrical conductivity increased up to $172 \mathrm{~S} \mathrm{~m}^{-1}$. Despite these positive results, more research is needed in order to define optimal contents and processing methods to consistently achieve these improvements. If these issues are increasingly controlled and the impact on other mechanical properties (such as compressive strength, and bending strength) is accurately estimated, it will be possible to use CNCs as a structural material in the near future. Future developments of CNCs will be developed for aerospace applications. CNCs might be applicable to propulsion systems and hot structures with interest in both $\mathrm{SiC}$-based and oxide composites. As reported by Steyer [1], whereas CMCs may be preferred for hot structure in hypersonic vehicles, CNC applications might be possible for materials supporting higher heat loads, such as ultra-high-temperature ceramics. Additionally, fundamental and applied research domains remain open for CNCs including, such as damage accumulation mechanisms/models, life predictions methodologies/modeling, nondestructive inspection techniques, and robust field and depot-level repair methods [1].

\section{Conflict of Interests}

The authors declare that there is no conflict of interests regarding the publication of this paper.

\section{Acknowledgments}

The corresponding author gratefully acknowledges the financial support given by FCT (Fundação para a Ciência e Tecnologia), in the context of the project "Modelling and Analysis of Nanostructures: Carbon Nanotubes and Nanocomposites" (PTDC/ECM/103490/2008). This work was supported by FCT, through IDMEC, under LAETA, project UID/EMS/ $50022 / 2013$.

\section{References}

[1] T. E. Steyer, "Shaping the future of ceramics for aerospace applications," International Journal of Applied Ceramic Technology, vol. 10, no. 3, pp. 389-394, 2013.

[2] T. Nozawa, T. Hinoki, A. Hasegawa et al., "Recent advances and issues in development of silicon carbide composites for fusion applications," Journal of Nuclear Materials, vol. 386-388, pp. 622-627, 2009.

[3] X.-M. Yu, W.-C. Zhou, F. Luo, W.-J. Zheng, and D.-M. Zhu, "Effect of fabrication atmosphere on dielectric properties of $\mathrm{SiC/SiC} \mathrm{composites,"} \mathrm{Journal} \mathrm{of} \mathrm{Alloys} \mathrm{and} \mathrm{Compounds,} \mathrm{vol.} \mathrm{479,}$ no. 1-2, pp. L1-L3, 2009.

[4] X.-H. Shi, J.-H. Huo, J.-L. Zhu et al., "Ablation resistance of SiC$\mathrm{ZrC}$ coating prepared by a simple two-step method on carbon fiber reinforced composites," Corrosion Science, vol. 88, pp. 49$55,2014$.

[5] X. Zhang, C. Liu, M. Li, and J. Zhang, "Research on toughening mechanisms of alumina matrix ceramic composite materials improved by rare earth additive," Journal of Rare Earths, vol. 26, no. 3, pp. 367-370, 2008.

[6] X. H. Zhang, C. X. Liu, M. S. Li, J. H. Zhang, and J. L. Sun, "Toughening mechanism of alumina-matrix ceramic composites with the addition of AlTiC master alloys and $\mathrm{ZrO}_{2}$," Ceramics International, vol. 35, no. 1, pp. 93-97, 2009.

[7] R. H. J. Hannink, P. M. Kelly, and B. C. Muddle, "Transformation toughening in zirconia-containing ceramics," Journal of the American Ceramic Society, vol. 83, no. 3, pp. 461-487, 2000.

[8] W.-C. Tu, F. F. Lange, and A. G. Evans, "Concept for a damagetolerant ceramic composite with 'strong' interfaces," Journal of the American Ceramic Society, vol. 79, no. 2, pp. 417-424, 1996.

[9] M. Schmücker, B. Kanka, and H. Schneider, “Temperatureinduced fibre/matrix interactions in porous alumino silicate ceramic matrix composites," Journal of the European Ceramic Society, vol. 20, no. 14-15, pp. 2491-2497, 2000.

[10] M. E. Westwood, J. D. Webster, R. J. Day, F. H. Hayes, and R. Taylor, "Oxidation protection for carbon fibre composites," Journal of Materials Science, vol. 31, no. 6, pp. 1389-1397, 1996.

[11] D. L. McDanels, "Analysis of stress-strain, fracture, and ductility behavior of aluminum matrix composites containing discontinuous silicon carbide reinforcement," Metallurgical Transactions A, vol. 16, no. 6, pp. 1105-1115, 1985.

[12] R. M. Laine and F. Babonneau, "Preceramic polymer routes to silicon carbide," Chemistry of Materials, vol. 5, no. 3, pp. 260279, 1993.

[13] X.-L. Su, W.-C. Zhou, F. Luo, Z.-M. Li, and D.-M. Zhu, "A cost-effective approach to improve dielectric property of $\mathrm{SiC}$ powder," Journal of Alloys and Compounds, vol. 476, no. 1-2, pp. 644-647, 2009.

[14] K. K. Chawla, Z. R. Xu, and J.-S. Ha, "Processing, structure, and properties of mullite fiber/mullite matrix composites," Journal of the European Ceramic Society, vol. 16, no. 2, pp. 293-299, 1996. 
[15] O. Vasylkiv, Y. Sakka, and V. V. Skorokhod, "Low-temperature processing and mechanical properties of zirconia and zirconiaalumina nanoceramics," Journal of the American Ceramic Society, vol. 86, no. 2, pp. 299-304, 2003.

[16] S. Sarkar and P. K. Das, "Effect of sintering temperature and nanotube concentration on microstructure and properties of carbon nanotube/alumina nanocomposites," Ceramics International, vol. 40, no. 5, pp. 7449-7458, 2014.

[17] O. Tapasztó, H. Lemmel, M. Markó, K. Balázsi, C. Balázsi, and L. Tapasztó, "The influence of sintering on the dispersion of carbon nanotubes in ceramic matrix composites," Chemical Physics Letters, vol. 614, pp. 148-150, 2014.

[18] P. Kun, O. Tapasztó, F. Wéber, and C. Balázsi, "Determination of structural and mechanical properties of multilayer graphene added silicon nitride-based composites," Ceramics International, vol. 38, no. 1, pp. 211-216, 2012.

[19] H. Porwal, S. Grasso, and M. J. Reece, "Review of grapheneceramic matrix composites," Advances in Applied Ceramics, vol. 112, no. 8, pp. 443-454, 2013.

[20] J.-P. Fan, D.-M. Zhuang, D.-Q. Zhao et al., "Toughening and reinforcing alumina matrix composite with single-wall carbon nanotubes," Applied Physics Letters, vol. 89, no. 12, Article ID 121910, 4 pages, 2006.

[21] L. S. Walker, V. R. Marotto, M. A. Rafiee, N. Koratkar, and E. L. Corral, "Toughening in graphene ceramic composites," ACS Nano, vol. 5, no. 4, pp. 3182-3190, 2011.

[22] X. J. Zhao, L. R. Xiao, Z. W. Zhao et al., "Fabrication and mechanical properties of silicon carbide-aluminum oxynitride nanocomposites," Ceramics International, vol. 40, no. 9, pp. 14295-14303, 2014.

[23] J. B. Casady and R. W. Johnson, "Status of silicon carbide $(\mathrm{SiC})$ as a wide-bandgap semiconductor for high-temperature applications: a review," Solid-State Electronics, vol. 39, no. 10, pp. 1409-1422, 1996.

[24] L. Latu-Romain and M. Ollivier, "Silicon carbide based onedimensional nanostructure growth: towards electronics and biology perspectives," Journal of Physics D: Applied Physics, vol. 47, no. 20, Article ID 203001, 18 pages, 2014.

[25] M. Parchovianský, D. Galusek, M. Michálek et al., "Effect of the volume fraction of $\mathrm{SiC}$ on the microstructure and creep behavior of hot pressed $\mathrm{Al}_{2} \mathrm{O}_{3} / \mathrm{SiC}$ composites," Ceramics International, vol. 40, no. 1, pp. 1807-1814, 2014.

[26] R. Barea, M. Belmonte, M. I. Osendi, and P. Miranzo, “Thermal conductivity of $\mathrm{Al}_{2} \mathrm{O}_{3} / \mathrm{SiC}$ platelet composites," Journal of the European Ceramic Society, vol. 23, no. 11, pp. 1773-1778, 2003.

[27] D. P. H. Hasselman and L. F. Johnson, "Effective thermal conductivity of composites with interfacial thermal barrier resistance," Journal of Composite Materials, vol. 21, no. 6, pp. 508-515, 1987.

[28] A. Sawaguchi, K. Toda, and K. Niihara, "Mechanical and electrical properties of $\mathrm{Al}_{2} \mathrm{O}_{3} / \mathrm{SiC}$ nano-composites," Journal of the American Ceramic Society, vol. 99, no. 6, pp. 510-513, 1991.

[29] D. Stauffer and A. Aharony, Introduction to Percolation Theory, Taylor \& Francis, 2nd edition, 1992.

[30] Y. L. Dong, F. M. Xu, X. L. Shi et al., "Fabrication and mechanical properties of nano-/micro-sized $\mathrm{Al}_{2} \mathrm{O}_{3} / \mathrm{SiC}$ composites," Materials Science and Engineering A, vol. 504, no. 1-2, pp. 49-54, 2009.

[31] D. Djenkal, D. Goeuriot, and F. Thevenot, "SiC-reinforcement of an $\mathrm{Al}_{2} \mathrm{O}_{3}-\gamma \mathrm{AlON}$ composite," Journal of the European Ceramic Society, vol. 20, no. 14-15, pp. 2585-2590, 2000.
[32] C.-Y. Bai, X.-Y. Deng, J.-B. Li et al., "Fabrication and properties of cordierite-mullite bonded porous $\mathrm{SiC}$ ceramics," Ceramics International, vol. 40, no. 4, pp. 6225-6231, 2014.

[33] A. Smirnov and J. F. Bartolomé, "Microstructure and mechanical properties of $\mathrm{ZrO}_{2}$ ceramics toughened by $5-20 \mathrm{vol} \% \mathrm{Ta}$ metallic particles fabricated by pressureless sintering," Ceramics International, vol. 40, no. 1, pp. 1829-1834, 2014.

[34] CoorsTek-Amazing Solutions, 2014, http://www.dynacer.com/ materials/silicon-carbide/.

[35] R. Benavente, M. D. Salvador, F. L. Penaranda-Foix, E. Pallone, and A. Borrell, "Mechanical properties and microstructural evolution of alumina-zirconia nanocomposites by microwave sintering," Ceramics International, vol. 40, no. 7, pp. 11291-11297, 2014.

[36] A. S. A. Chinelatto, A. L. Chinelatto, C. L. Ojaimi, J. A. Ferreira, and E. M. D. J. A. Pallone, "Effect of sintering curves on the microstructure of alumina-zirconia nanocomposites," Ceramics International, vol. 40, no. 9, pp. 14669-14676, 2014.

[37] I. Danilenko, F. Glazunov, T. Konstantinova, G. Volkova, and V. Burkhovetski, "Effect of oxide nanofillers on fabrication, structure, and properties of zirconia-based composites," Journal of the European Ceramic Society, vol. 33, no. 12, pp. 2321-2325, 2013.

[38] CoorsTek-Amazing Solutions, 2014, http://www.dynacer.com/.

[39] Technox zirconia-CoorsTek_Amazing Solutions, 2014, http:// www.dynacer.com/materials/zirconia/.

[40] J. Cho, A. R. Boccaccini, and M. S. P. Shaffer, "Ceramic matrix composites containing carbon nanotubes," Journal of Materials Science, vol. 44, no. 8, pp. 1934-1951, 2009.

[41] M. Estili, A. Kawasaki, H. Sakamoto, Y. Mekuchi, M. Kuno, and T. Tsukada, "The homogeneous dispersion of surfactantless, slightly disordered, crystalline, multiwalled carbon nanotubes in $\alpha$-alumina ceramics for structural reinforcement," Acta Materialia, vol. 56, no. 15, pp. 4070-4079, 2008.

[42] K. G. Dassios, P. Alafogianni, S. K. Antiohos, C. Leptokaridis, N. Barkoula, and T. E. Matikas, "Optimization of sonication parameters for homogeneous surfactant-assisted dispersion of multiwalled carbon nanotubes in aqueous solutions," The Journal of Physical Chemistry C, vol. 119, no. 13, pp. 7506-7516, 2015.

[43] N. A. Fedosova, P. P. Faikov, N. A. Popova et al., "Effect of the nature of carbon nanotubes on the structure and strength of ceramic composites," Glass and Ceramics, vol. 71, no. 3-4, pp. 128-131, 2014.

[44] J. Hilding, E. A. Grulke, Z. G. Zhang, and F. Lockwood, "Dispersion of carbon nanotubes in liquids," Journal of Dispersion Science and Technology, vol. 24, no. 1, pp. 1-41, 2003.

[45] M. Estili and A. Kawasaki, "An approach to mass-producing individually alumina-decorated multi-walled carbon nanotubes with optimized and controlled compositions," Scripta Materialia, vol. 58, no. 10, pp. 906-909, 2008.

[46] D. Jiang, K. Thomson, J. D. Kuntz, J. W. Ager, and A. K. Mukherjee, "Effect of sintering temperature on a single-wall carbon nanotube-toughened alumina-based nanocomposite," Scripta Materialia, vol. 56, no. 11, pp. 959-962, 2007.

[47] G.-D. Zhan, J. D. Kuntz, J. Wan, and A. K. Mukherjee, "Singlewall carbon nanotubes as attractive toughening agents in alumina-based nanocomposites," Nature Materials, vol. 2, no. 1, pp. 38-42, 2003.

[48] A. Aguilar-Elguézabal and M. H. Bocanegra-Bernal, "Fracture behaviour of $\alpha-\mathrm{Al}_{2} \mathrm{O}_{3}$ ceramics reinforced with a mixture of 
single-wall and multi-wall carbon nanotubes," Composites Part B: Engineering, vol. 60, pp. 463-470, 2014.

[49] A. Peigney, C. Laurent, F. Dobigeon, and A. Rousset, "Carbon nanotubes grown in situ by a novel catalytic method," Journal of Materials Research, vol. 12, no. 3, pp. 613-615, 1997.

[50] A. Peigney, C. Laurent, E. Flahaut, and A. Rousset, "Carbon nanotubes in novel ceramic matrix nanocomposites," Ceramics International, vol. 26, no. 6, pp. 677-683, 2000.

[51] K. G. Dassios, G. Bonnefont, G. Fantozzi, and T. E. Matikas, "Novel highly scalable carbon nanotube-strengthened ceramics by high shear compaction and spark plasma sintering," Journal of the European Ceramic Society, vol. 35, no. 9, pp. 2599-2606, 2015.

[52] A. Gallardo-López, R. Poyato, A. Morales-Rodríguez, A. Fernández-Serrano, A. Muñoz, and A. Domínguez-Rodríguez, "Hardness and flexural strength of single-walled carbon nanotube/alumina composites," Journal of Materials Science, vol. 49, no. 20, pp. 7116-7123, 2014.

[53] O. Hanzel, J. Sedláček, and P. Šajgalík, "New approach for distribution of carbon nanotubes in alumina matrix," Journal of the European Ceramic Society, vol. 34, no. 7, pp. 1845-1851, 2014.

[54] X. Wang, N. P. Padture, and H. Tanaka, "Contact-damageresistant ceramic/single-wall carbon nanotubes and ceramic/ graphite composites," Nature Materials, vol. 3, no. 8, pp. 539544, 2004.

[55] M. Estili and Y. Sakka, "Recent advances in understanding the reinforcing ability and mechanism of carbon nanotubes in ceramic matrix composites," Science and Technology of Advanced Materials, vol. 15, no. 6, Article ID 064902, 2014.

[56] M. Estili and A. Kawasaki, "Engineering strong intergraphene shear resistance in multi-walled carbon nanotubes and dramatic tensile improvements," Advanced Materials, vol. 22, no. 5, pp. 607-610, 2010.

[57] K. G. Dassios, "Carbon nanotube-reinforced ceramic matrix composites: processing and properties," in High Temperature Ceramic Matrix Composites 8: Ceramic Transactions, L. Zhang and D. Jiang, Eds., vol. 248, pp. 133-157, Wiley, 2014.

[58] F. Inam, T. Vo, and B. R. Bhat, "Structural stability studies of graphene in sintered ceramic nanocomposites," Ceramics International, vol. 40, pp. 16227-16233, 2014.

[59] M. J. de Andrade, M. D. Lima, C. P. Bergmann et al., "Carbon nanotube/silica composites obtained by sol-gel and highpressure techniques," Nanotechnology, vol. 19, no. 26, Article ID 265607, 7 pages, 2008.

[60] C. Zheng, M. Feng, X. Zhen, J. Huang, and H. Zhan, "Materials investigation of multi-walled carbon nanotubes doped silica gel glass composites," Journal of Non-Crystalline Solids, vol. 354, no. 12-13, pp. 1327-1330, 2008.

[61] T. He, J. Li, L. Wang, J. Zhu, and W. Jiang, "Preparation and consolidation of alumina/graphene composite powders," Materials Transactions, vol. 50, no. 4, pp. 749-751, 2009.

[62] A. Centeno, V. G. Rocha, B. Alonso et al., "Graphene for tough and electroconductive alumina ceramics," Journal of the European Ceramic Society, vol. 33, no. 15-16, pp. 3201-3210, 2013.

[63] Y.-F. Chen, J.-Q. Bi, C.-L. Yin, and G.-L. You, "Microstructure and fracture toughness of graphene nanosheets/alumina composites," Ceramics International, vol. 40, no. 9, pp. 13883-13889, 2014.

[64] K.-D. Wang, Y.-B. Jia, Z.-J. Lai, and Y.-F. Liu, "Ab initio study on ionization energies of 3-amino-1-propanol," Chinese Journal of Chemical Physics, vol. 24, no. 3, pp. 315-318, 2011.
[65] H. J. Kim, S.-M. Lee, Y.-S. Oh et al., "Unoxidized graphene/ alumina nanocomposite: fracture- and wear-resistance effects of graphene on alumina matrix," Scientific Reports, vol. 4, article 5176, 10 pages, 2014.

[66] P. Hvizdoš, J. Dusza, and C. Balázsi, "Tribological properties of $\mathrm{Si}_{3} \mathrm{~N}_{4}$-graphene nanocomposites," Journal of the European Ceramic Society, vol. 33, no. 12, pp. 2359-2364, 2013.

[67] E. L. Corral, L. S. Walker, V. R. Marotto, M. A. Rafiee, and N. Koratkar, "Graphene-Reinforced Ceramic Composites and Uses Therefor,” Patent 20130184143, 2013. 

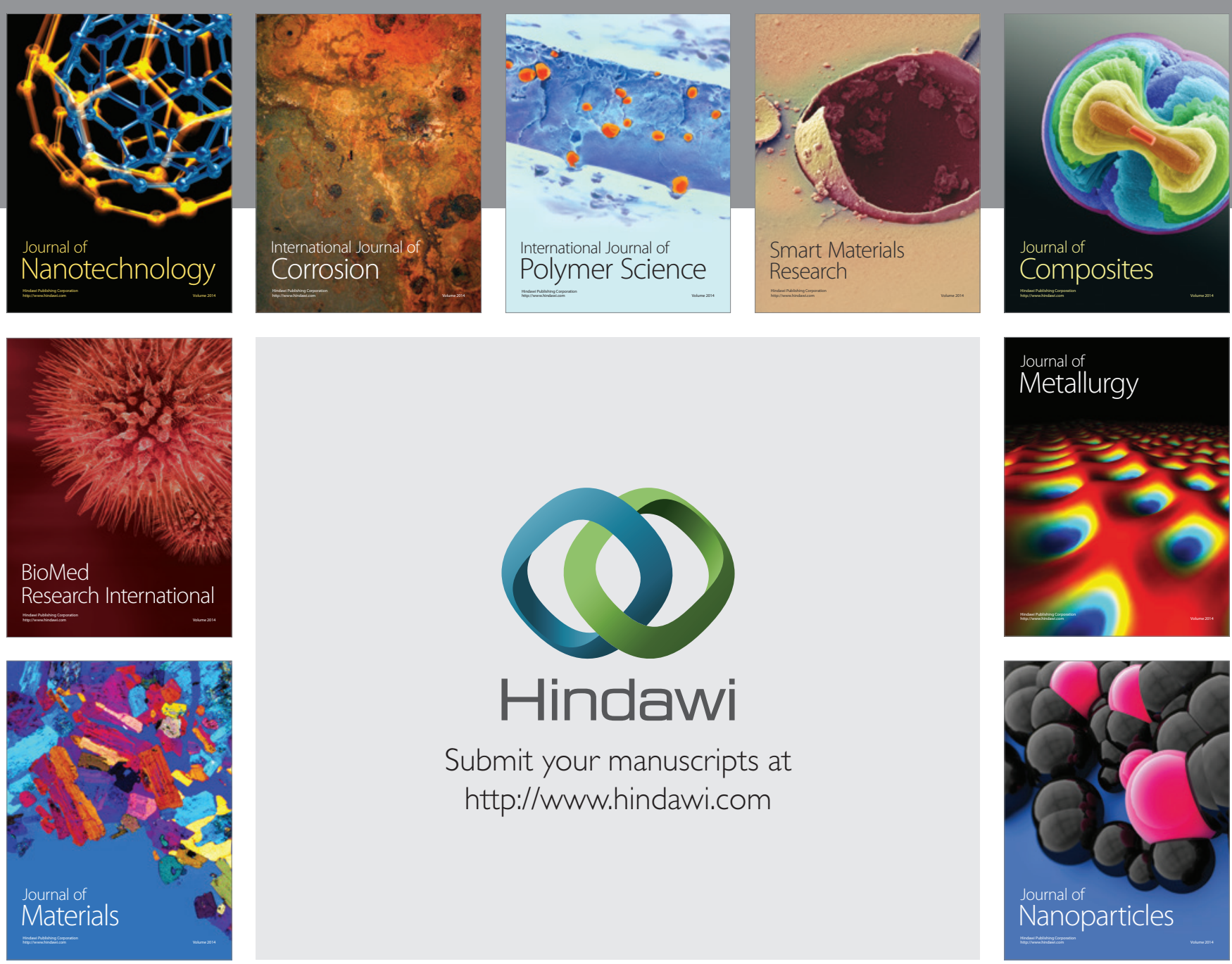

Submit your manuscripts at http://www.hindawi.com
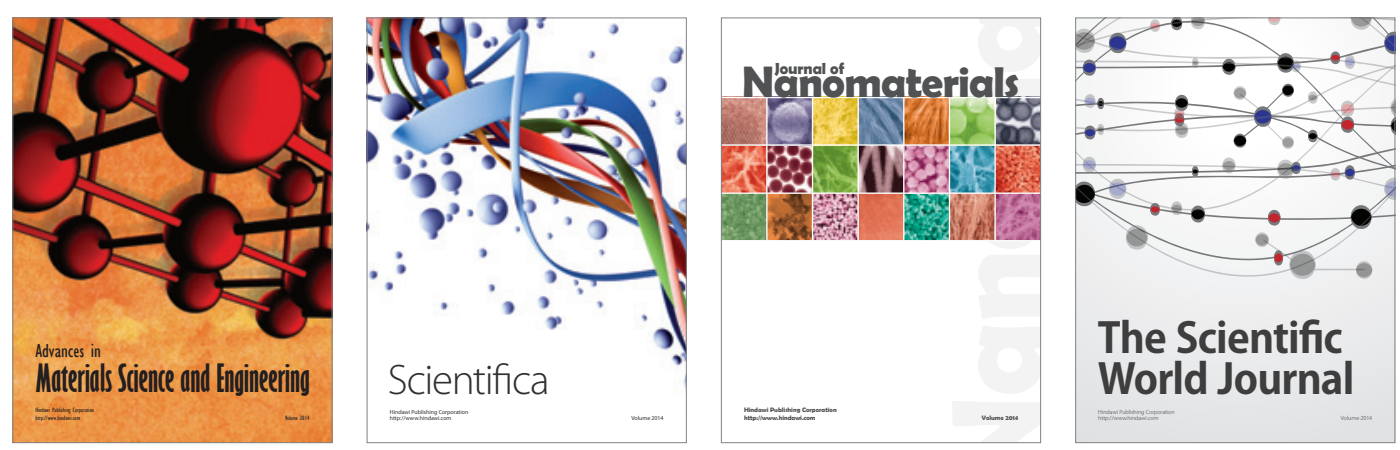

\section{The Scientific World Journal}
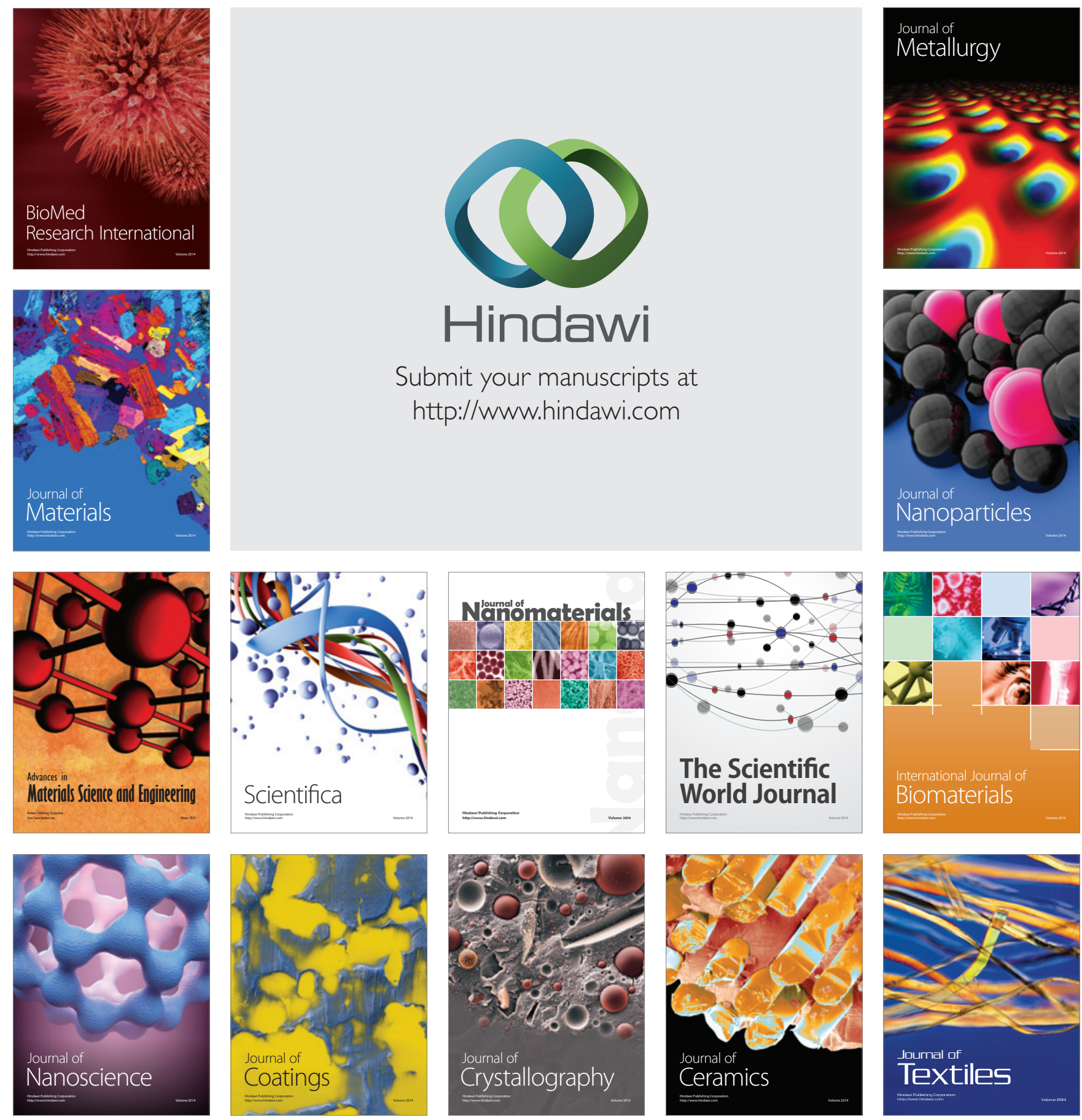